\title{
Improving
}

\section{Demands and tasks of intercultural school development: Group discussions with experts about intercultural school development}

Improving Schools 2018, Vol. 2I(I) 84-10I

(c) The Author(s) 2017

Reprints and permissions: sagepub.co.uk/journalsPermissions.nav DOI: $10.1177 / 1365480217708897$ journals.sagepub.com/home/imp

丹SAGE

\section{Marcus Syring}

Ludwig-Maximilians-University of Munich, Germany

\section{Teresa Tillmann}

Ludwig-Maximilians-University of Munich, Germany

\section{Nicole Sacher}

Ludwig-Maximilians-University of Munich, Germany

\author{
Sabine Weiß \\ Ludwig-Maximilians-University of Munich, Germany
}

\section{Ewald Kiel}

Ludwig-Maximilians-University of Munich, Germany

\begin{abstract}
The present study is aimed at identifying demands and tasks that are considered important by experts in the field of interculturalism for the successful development of schools. Although different theoretical models about intercultural school development, incorporating various conditions and dimensions, have already been suggested, gaps in research on the specific content of various administrative levels of school as an educational institution can still be identified. In order to fill those gaps, we conducted group discussions with small groups of experts in the field of interculturalism. Experts were matched into three groups so that each represents a high level of diversity regarding their particular expertise. Results from the discussions were investigated by applying content analysis. Based on the revealed findings, five fields of action can be established that are essential for the process of intercultural school development. The revealed areas covered a variety of factors, ranging from individual reflection to developmental processes of a school as an organization. In the present study, those facets are interpreted as conditions under which successful intercultural school development processes can be established. While most content areas can be mapped to
\end{abstract}

\section{Corresponding author:}

Marcus Syring, Department of Education and Rehabilitation, Ludwig-Maximilians-University of Munich, Leopoldstrasse 13, 80802 Munich, Germany.

Email: marcus.syring@edu.Imu.de 
the existing theoretical models, they add further information with regard to the content of the theoretical dimensions. This is particularly the case at the individual level. Resulting practical implications are explained and further discussed on the basis of inevitable future research.

\section{Keywords}

Demands, expert group discussion, interculturalism, school development

\section{Introduction}

The importance of intercultural school development has increased over the last few years. One important reason for this development is an ongoing migration to the EU-28. On 1 January 2014, 19.6 million third-country nationals were living in the EU-28 (this corresponds to $3.9 \%$ of the population of the EU-28). Furthermore, 33.5 million people who were born outside the European Union (EU) are currently living in the EU (Eurostat, 2015). Comparing the age structure of the EU-28 population to that of the migrants, the migrants are much younger on average. For example, in Germany, more than one-third of the children under the age of 10 have a migrant background (Action Commission Education [Aktionsrat Bildung], 2016). The United Kingdom, Spain, Italy, Belgium and France also have similar proportions of children with migrant backgrounds (Eurostat, 2015). This situation has political, social, economic and demographic consequences.

One way to systemize those consequences for schools is by drawing on already existing theoretical approaches that describe dynamics leading to changes in schools. As one example, the 'innovation cube' of Schratz and Steiner-Loeffler (1999) defines three dimensions that are important for initiating school development processes (see Figure 1). The first dimension describes the direction particular suggestions arise from. They can either be 'bottom up', meaning from teachers or students, or 'top down', implying changes forced by higher authorities. The question of whether those suggestions are brought to them from 'inside' or 'outside' is represented by the second dimension. Propositions from members of a school community would serve as the 'inside dimension' and political factors or external institutions would be the 'outside dimension'. The third and final dimension describes the aspects of 'pull' or 'push'. For example, while an attractive goal would fall into the pull category, 'push' would imply regulations dictated by school authorities.

However, due to the current developmental political, social, economic and demographic situation mentioned above, the more recent focus of the public lies primarily on requirements that would belong to the 'top down', 'outside' and 'push' dimensions in the model. Migration does not only affect Europe, it is a global phenomenon. Globally, more than 231 million people were represented in the international migrant group in 2013. In many countries and bigger cities, such as Sydney, London and New York, more than one-third of the populations have a migration background, while in other cities, such as Brussels, migrants represent half of the total number of residents or even more (International Organization for Migration, 2015). Of these migrants, about 15 percent are younger than 20 years of age, which would imply a relatively high number of students who are still within compulsory education (United Nations Department of Economic and Social Affairs [UN DESA], 2013). These cited migration processes contribute significantly to the ongoing process of globalization (e.g. Giddens, 1999; McLuhan, 1962). Close contact to other cultures as well as international commitment and obligations are part of everyday life and limit national sovereignty.

However, school development processes that are initiated based on the opposite movements ('bottom up', 'inside' and 'pull') exist, but to this point have been neglected. Teachers' motivation to pursue a training that would help them consider the heterogeneity of all their students in a more effective and appropriate way can be seen as one example of such a situation. This would represent 


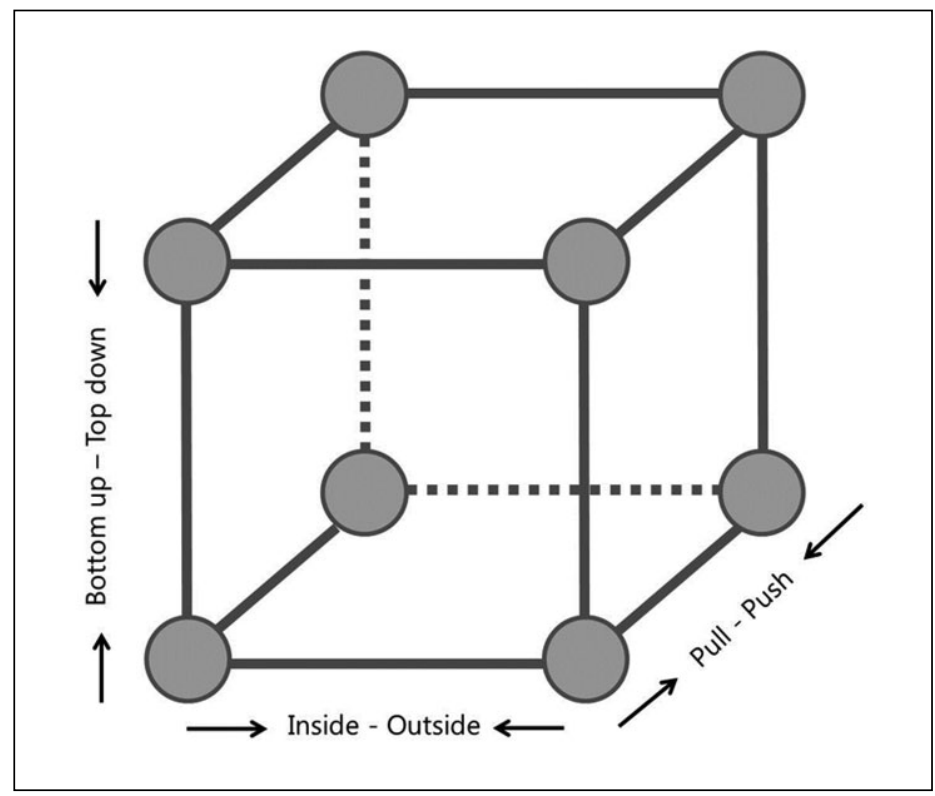

Figure I. 'Innovation cube' by Schratz and Steiner-Loeffler (1999).

the 'bottom up', 'inside' and 'pull' dimensions because teachers themselves want to initiate school development processes.

As can be seen in the description above, there are some theoretical and empirical approaches that aim at describing the reasons for school development. But at the same time, there is still a significant lack of research around them, and questions regarding concrete content of those school development processes still remain unanswered. Moreover, these are significant questions raised under the present demographic and political conditions. In addition, the focus of the public view is on external factors that impose intercultural changes on schools. Therefore, the present study addresses the question of concrete information on intercultural school development processes and the stated research gap. First, it aims at expanding already established models for school development with a summary of experts' views and ideas, while, second, taking demands that originate inside the schools particularly into account.

\section{Theoretical background and current state of empirical research}

The upcoming sections will focus on various theories and definitions within the academic field of intercultural school development, which represent the theoretical basis for this article. After introducing the field of interculturalism through definitions of the term 'culture', it is subsequently transferred to educational contexts, which merges into a first definition of intercultural school development. After summarizing the two major scientific approaches to interculturalism (immigration and intercultural pedagogy), its meaning for educational contexts is introduced. Following this introduction of terms, a model of school development by Dalin, Rolff, and Kleekamp (1993) is introduced and completed by a model of intercultural school development by Karakaşoğlu, Gruhn, and Wojciechowicz (2011), which will then lead into the second section, summarizing the theoretical background and leading to the research questions of this article. 


\section{Interculturalism and school}

Developing a universally accepted definition of the term 'culture' is almost impossible despite its significant role in the discussion of interculturalism. One main reason is the 'indefinite' nature of the term already bemoaned in the Age of Enlightment (e.g. Herder, 1995, original publication 1784-1791). Herder's assumption that cultures basically represent national dispositions was valid until the modern era. One famous example is Ruth Benedict's (1954) 'The Chrysanthemum and the Sword: Patterns of Japanese Culture'. Benedict and many other anthropologists of her time were influenced by Franz Boas, a German-American pioneer of anthropology who was well aware of German philosophers like Herder.

Postmodernist interpretations (see Kiel, Syring, \& Weiss, 2016) did not agree on reducing the term to ethnical and national particularities. Therefore, a rather open conceptualization of culture, such as that presented by Hall (1997), would be helpful for a definition of the term 'interculturalism' for this article because it enables the inclusion of changes of reality and society, such as migration, globalization and the necessary growth of equal participation. Culture can, therefore, be seen as historically grown but, at the same time, perceived as incomplete and inconsistent due to its steady progressiveness.

Interculturalism, based on such a broad definition of culture, is seen as open and changeable, as well as being dependent on the challenges resulting from different societal and political circumstances. One strand of discussion defines it as a way people with different cultural scripts get along with each other. It seeks opportunities for tolerance and the handling of conflicts arising from different sets of values, orientation patterns and normatively accepted actions. Due to the differentiation and complexity of modern societies, those scripts in terms of values, orientation patterns and accepted actions are not nationally or geographically bound but, rather, can be found not only inside one state or society but also in individuals themselves. Even individuals can be seen as cultural hybrids; for example, a Muslim living in Germany, in favour of Islamic values, celebrating Christmas, supporting female higher education and making women autonomous is just such a cultural hybrid.

First approaches for transferring such an understanding to the educational context in forms of intercultural school development can be found over the last decades. For example, the 1970s workrelated migration process in Germany is defined as the beginning of the discussion about migration in the educational field. The number of children from foreign families in the schools challenged the field of pedagogy to develop new school development models (e.g. Karakaşoğlu et al., 2011). In response, the so-called immigrant pedagogics aimed at stabilizing foreign identities and supporting integration in the new social environment. These two differentiating and categorizing discussions and the critical evaluation of their implications led to a constant further development of the understanding of interculturalism in the educational scientific field.

Similarly, three opposing trends are also found in the parts of educational sciences that are engaged in culture at present. First, following the social-philosophical approach of Honneth (1996), intercultural pedagogy demands an appreciation of different cultures. It further assumes that knowledge of the differences among the various groups helps to develop an understanding and to avoid prejudices and discrimination. Differences between cultures are not denied; rather, they are noticed and acknowledged (Kiel et al., 2016).

On the other hand, there is the second position, implying that highlighting cultural differences should consequently be avoided. In line with this is the assumption that people take on dominant roles simply by defining differentness (Hall, 1997). Explanations of this more constructivist approach are assumed to be influenced by postmodern philosophy and theories on stigmatization, as both imply postulations of consequent decategorization. Based on its acceptance of and response 
to the criticism that the field of intercultural pedagogy faces, it continues to evolve. Thus, the reflexive intercultural pedagogy calls for a critical reflection of cultural interpretative models by questioning its own meaning and impact (Hall, 1997).

A third approach, the Diversity Approach, includes other categories that are related to degradation and defamation. These include characteristics that can be observed externally, such as skin colour, disability or gender, but also include subjective and more inner and societal-cultural dimensions. Characteristics such as education, religion, nationality and ethnical affiliation would also be considered in this theory (Hall, 1997).

The question regarding the formation and particular nature of intercultural school development is influenced by the partly opposing positions described above. Yet, another important question is how to deal with languages within educational institutions. The decategorizing approach prohibits the assignment of German as the only educational language in schools because it would imply that other languages are devalued as deficits. A radical continuation of this approach is the concept of translanguaging, which demands the absolute equal status of all languages in the classroom as an expression of cultural diversity within schools. However, this approach has not offered any concepts that would be applicable in practical settings (Kiel et al., 2016).

\section{Dalin's model of school development}

The term school development, as well as the concept related to it, is based on a foundation with a long tradition. In the current Western European scientific discussion, a shift in responsibilities away from the centralized school administration towards single schools is further emphasized. School development processes are then defined as having to be realized in the individual schools themselves (Dalin, 2005). This goes back to the so-called New Public Management, which focuses on the learning and self-development of organizations. First seen in the 1970s, it addresses all areas of school development, such as the organizational level, teaching and classroom development. It represents an opposing position to the classic bureaucratic model of Max Weber which acts on the assumptions of hierarchical models (e.g. Haque, 2004). In line with these conceptual definitions of school development, well-established theories can be identified in the international field of school development. A particular focus of recent concepts in Germany and Europe lies in supporting the concepts of New Public Management. This is realized through the concept of Dalin and his colleagues (Dalin, 1978, 2005; Dalin et al., 1993), which is seen as one of the most influential models. They explain the interaction condition between society, or the school system, and the single school with a focus on the particular needs and forces regarding initiating school development processes. Based on this concept, changes can only be established sustainably if societal needs are also included. In addition, change is not seen as a linear process, but rather a mutual process of development and adjustment. All participants and members of a system, including individuals, groups and institutions, play essential roles. Dalin $(1978,2005)$ also defines the single school as a 'motor for development'. His model represents the relations between systems that are represented through three levels: human resource development, development of teaching and organizational development. In addition, it covers other developmental aspects, such as teaching, parental cooperation and staff competencies (e.g. Lahdenperä, 2009). In this model, all participants of the school system are addressed: teachers, principals, politicians and authorities.

In summary, two leading basic ideas for the application of school development can be described. On one hand, the single school acts as a central point for the initiation of school development. On the other hand, and at the same time, schools should not be seen as isolated institutions, but rather in relation to their local and regional connectedness. 


\section{Intercultural school development}

Intercultural school development has been discussed more actively in recent years (Catarci \& Fiorucci, 2016). This is mainly due to the interrelation of the two differing pedagogical approaches towards interculturalism as mentioned above, as well as the present demographic development and related challenges regarding the increasing heterogeneity of actors in schools (e.g. Action Commission Education [Aktionsrat Bildung], 2016). However, the process of developing schools interculturally is often defined in two ways: as a change in the view of schools based on the societal situation, and as the adjustment of schools towards the heterogeneity of students. In particular, a change in students' attitudes is prevented and, rather, it is suggested that schools have to change. The needs of particular actors represent the basis for methods of development and support. As already described in the section about general school development (see section 'Dalin's model of school development'), this is also meant to take place on the organizational level. Furthermore, it is emphasized that all levels must be included (e.g. Karakaşoğlu et al., 2011). These conceptualizations of intercultural school development are also supported by the vast majority of academic discussions. However, analysing the already existing theoretical and empirical suggestions and models, it appears that a systematic summary of this process is still missing (see Table 2). Nevertheless, there are meaningful and important theories related to intercultural school development processes in the German field of intercultural school development that tie in with the recent strong European development towards concepts based on Dalin's $(1978,2005)$ work. One of those is Karakaşoğlu and her colleagues' (2011) model, which will be the theoretical foundation on which the present study is based (see Figure 2). It is based on the three dimensions that were first suggested by Dalin (1978, 2005; Dalin et al., 1993) and describes the different levels of the educational institution school: the structural, the content-related and the social as well as the personal level of activity. On the personal level, the training and education of teachers are focused on. Factors such as demographic change, migration processes, (inter-)cultural competences and many others are included on this level. The content-related, didactic and curricular levels focus on the formation of competences, learning goals and educational standards on the basis of tolerance and acceptance.

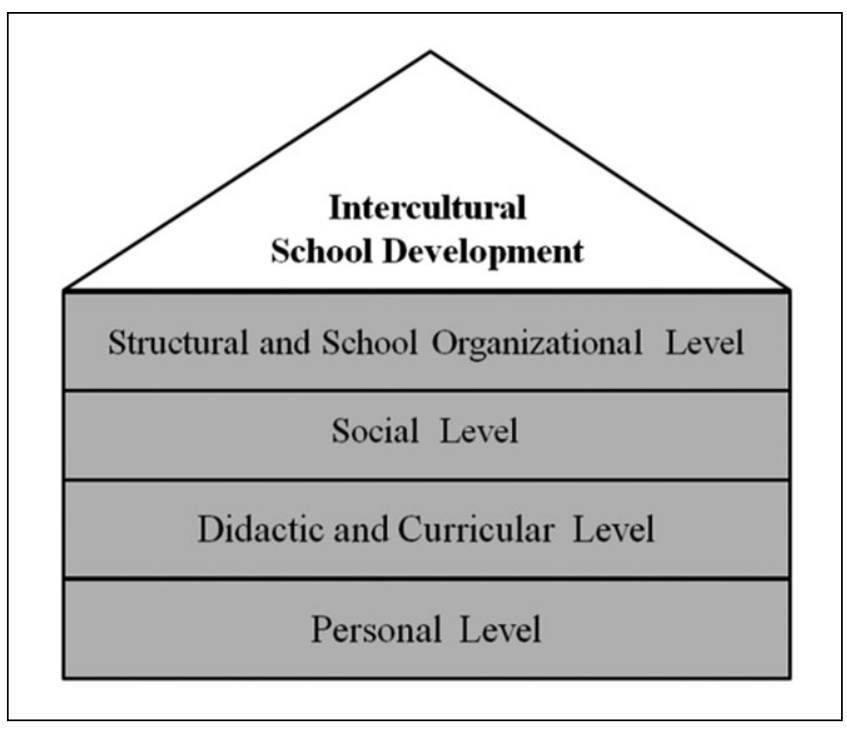

Figure 2. Model of intercultural school development by Karakaşoğlu et al. (201 I). 
The introduction of a new value system for teachers represents the focus of the structural organizational level. This includes cooperation with institutions outside of school as well as the change and adjustment of organizational levels of school. The last, the social level, suggests the establishment of new kinds of interactions. This should be realized by answering questions about the use of language and should be based on principles such as acceptance, tolerance and recognition.

\section{Conclusion based on the current state of research and research questions}

In the section above, it was shown that existing points of view about school development, and particularly the intercultural school development process, mostly result from theoretical models which include different levels, dimensions and groups of people. As an example, the model developed by Karakaşoğlu and colleagues (2011), based on conceptualizations by Dalin and colleagues (1993; Dalin, 1978, 2005), describes four of these dimensions. However, the different levels in all these models do not include sufficient practical and applicable information. This is because a definition of concrete tasks and demands that are particularly important for intercultural school development has not yet been empirically analysed.

The present study therefore addresses this lack of research by differentiating the various levels and dimensions in an empirical way. In order to do this, experts are asked about particular demands and tasks which are then collected and, subsequently, empirically and statistically analysed. This goal is based on the following research question: Which demands and tasks (such as structures, measures, procedures, cooperation, attitudes, etc.) for the successful intercultural school development are identified by the experts that further concretize established theoretical and empirical assumptions?

\section{Method}

The present study was part of the project 'School for Everyone', which is conducted by the chair of school pedagogy of the Ludwig-Maximilians-University Munich in cooperation with the city of Munich. The project is financially supported by the European Union/Asylum, Migration and Integration Fund (AMIF), under grant number AM14-00208 (funding period 2015-2018) and focuses on intercultural development of schools and educational institutions. The present study represents the preliminary step, including the empirically supported analyses of demands, and aims at analysing (organizational) structures, measures, collaborations and attitudes that are essential to initiate the achievement of those aspirations. Achieving an increase in educational opportunities and establishing a teaching culture that is aware of diversity-related issues are two goals of the present study.

\section{Data collection procedure and sample}

In total, 12 experts with a variety of theoretical, empirical and methodological experiences in the field of intercultural school development participated in the workshop and the group discussion. All participants were assigned by the responsible researchers to three smaller groups based on a strategy that represented the aforementioned diversity and aimed at a broader basis for argumentation and information (see Agar \& MacDonald, 1995; Hollander, 2004). This procedure ensured covering a variety of viewpoints and experiences. In particular, each group consisted of people representing different professional fields. Those were as follows: at least one expert engaged in 
'interculturalism and school'; one or two professors of a chair of school research from a university in Bavaria, Germany; as well as one or two people from the field of intercultural education. People in this last group often worked in different departments of the government or research institutions in Munich, Germany.

A 1-hour discussion followed the structure of investigative group discussions (see Barbour, 2007; Morgan, 1997) and aimed at engaging experts in a discussion to reveal participants' experiences, attitudes and opinions through stimulation by asking for more details or examples. Results are seen as collective patterns of orientation and represent a framework for articulation. Therefore, the focus of these discussions is not common experiences, but rather the exposure of personal relevance, reasoning and explanations by the participants, which is not possible in individual interviews. In the present study, the structure was followed through one leading question: 'Which structures, methods, cooperation and attitudes are essential for an intercultural school development process, and which ones are of particular importance?' Everything mentioned by the experts in response to this particular question throughout the discussion was collected and written down on prompt cards. In cases in which an aspect was mentioned by more than one participant, it was only written down once. Those cards were subsequently put on a board and represented the basis for further discussions. Those individual aspects on the cards represented the basis for further discussions (for further information on the methodological process, see Kiel et al., 2016). Each group was assigned two members of the responsible research staff from the study: one researcher in the project and one experienced researcher, who were responsible for the written recording of the contributions. First, everything that was mentioned was written and saved on prompt cards; later, in the discussion, they were posted so that they were visible to all participants. The described data collection process followed common ethical standards.

\section{Data analysis}

The goal of the present study was to develop categories and groups of tasks based on the protocols that were created during the three group discussions. In order to ensure that everything which is essential to the participants was included in the results, categories were developed inductively based on the material, following summarizing qualitative content analysis (e.g. Hsieh \& Shannon, 2005; Mayring, 2000). The protocols of the discussions represent the data basis for all analyses conducted. In these protocols, the discussion was recorded in detail in writing, which included all demands and tasks that were mentioned throughout the discussions. Every time an aspect was mentioned, it was counted and treated as a 'nomination' in the following content analysis. A coding manual with explanations and examples, as well as descriptions of intersections and classifications, was used to create the categorical system following the underlying raw material (see Coffey \& Atkinson, 1996; Morse \& Field, 1995; Patton, 2002). When a large number of different examples and demands were mentioned, sub-categories were created. The computer program MAXQDA (2011) was applied to classify the demands and tasks mentioned by the participants and recorded during group discussions. A final analytical step included a grouping process in order to create overarching fields of action. All categories can be found in the 'Results' section (see section 'Categories and codings'), while a description of all categories will be presented in section 'Description of the categories'.

\section{Coding, coder agreement and validation}

Using the function in the computer program MAXQDA, the inter-rater agreement was calculated for all overarching fields of action, categories and sub-categories. The analysis revealed an overall 
result of above 90 percent based on the total number of 524 codings, which is interpreted as good. However, in a few categories, coders agreed on less than 80 percent, which was defined as the minimum for the present study based on Bos (1989), who defined an acceptable inter-rater agreement as lying around 70 percent. In those cases, a discussion representing a communicative validation process based on the protocols revealed during the group discussions was applied (e.g. Kvale, 1995 ) in order to solve the issue and find agreement. More detailed information on particular percentages for all groupings can be found in section 'Categories and codings'.

\section{Results}

\section{Categories and codings}

It is important to first present Table 1, which represents all groupings with the number of times the particular demand was mentioned by the experts, before describing the resulting categories in more detail.

\section{Description of the categories}

The following groups are summaries of five areas of action that were mentioned during the group discussions. Among all demands and tasks that were mentioned by the experts with regard to the intercultural school development processes, the following groups were revealed:

- Rethink attitudes and values (66 nominations),

- Enable and apply reflection (59 nominations),

- Advance instruction (52 nominations),

- Address human resource development actively and promote social cooperation (120 nominations),

- Develop the organization 'school' as a whole (184 nominations).

In the following section, the categories of the areas of tasks mentioned above will be described (declarations in parentheses represent the number of nominations), explained and supported with examples. The quotations refer to original statements by the experts and have not been changed in grammar and sentence construction. The indication of the source refers to the respective speaker.

Rethink attitudes and values. This first category describes the need to develop awareness for intercultural issues as well as intercultural attitudes. This is supposed to be realized through living interculturalism in schools. These demands and tasks mentioned affected all people involved in school similarly:

To live interculturalism demands more from a school than presenting interculturalism by valuing foreign food in attempted procedures. Schools have to find possibilities to transfer intercultural way of living as a real attitude and integrate it steadily into everyday school life. [Exp_3_Gr1]

The concrete application could be realized through acknowledging cultural variety, heterogeneity, and diversity (10) as well as the appreciation of diversity in language and language competencies (18). With regard to handling various languages, the experts mentioned the importance of agreeing on a consistent use of language and question whether it is useful and up to date to use only the native language of the particular country, such as German in this case, in the 
Table I. List of resulting categories and sub-categories mentioned by the experts, displaying the total amount of nominations ('total'), the correlations of codings ('corr') as citations that have conformingly been assigned to a particular category, the non-correlating citations ('non') and proportional inter-rater agreement rates ('\%').

\begin{tabular}{|c|c|c|c|c|}
\hline & total & corr & non & $\%$ \\
\hline Rethink attitudes and values & 66 & 65 & 15 & 98 \\
\hline Develop intercultural awareness and attitudes & 14 & 16 & 6 & 88 \\
\hline Live interculturalism in everyday school life & 6 & 3 & 7 & 50 \\
\hline Acknowledge cultural variety, heterogeneity and diversity & 10 & 10 & 0 & 100 \\
\hline Appreciate diversity in languages and language competences & 18 & 18 & 0 & 100 \\
\hline Develop ‘humanistic ethos' & 18 & 18 & 2 & 100 \\
\hline Enhancement: appreciation/accepting/valuing & $(4)$ & (5) & $(\mathrm{I})$ & $(80)$ \\
\hline Develop sensitivity and empathy & (6) & (5) & (I) & $(83)$ \\
\hline Neutralize orientation on deficits and developing subjectivation & $(8)$ & (8) & $(0)$ & $(100)$ \\
\hline Enable and apply reflection & 59 & 62 & 7 & 95 \\
\hline Self-reflection and change of perspective & 39 & 37 & 2 & 95 \\
\hline Self-reflection of own migration background & $(4)$ & (4) & $(0)$ & $(100)$ \\
\hline Take different levels and roles into account & $(\mathrm{II})$ & $(10)$ & $(\mathrm{I})$ & $(91)$ \\
\hline Learn (self-)reflection/change of perspective & $(24)$ & $(23)$ & $(\mathrm{I})$ & (96) \\
\hline Enable concrete and practical application & 2 & 2 & 0 & 100 \\
\hline Disassociate from charged terms & 4 & 5 & I & 80 \\
\hline Gear towards 'inclusion' & 5 & 8 & 3 & 63 \\
\hline Recognize problems/develop problem awareness & 6 & 6 & 0 & 100 \\
\hline Take up criticism of power & 3 & 4 & $\mathrm{I}$ & 75 \\
\hline Advance instruction & 53 & 58 & 5 & 91 \\
\hline Broaden internal differentiation & 5 & 5 & 0 & 100 \\
\hline Consider language promotion and learning (students) & 14 & 17 & 3 & 82 \\
\hline Gear towards students & 8 & 9 & 1 & 89 \\
\hline Enable education for all & $(4)$ & (5) & (I) & 80 \\
\hline Create identity/self-confidence & $(4)$ & (4) & $(0)$ & 100 \\
\hline Enhance concepts, methods and material for teaching & 20 & 20 & 0 & 100 \\
\hline Consider pedagogical-didactical concepts & 4 & 5 & 1 & 80 \\
\hline Review hidden curriculum & 2 & 2 & 0 & 100 \\
\hline Address human resource development actively and promote social cooperation & 120 & 116 & 14 & 97 \\
\hline Adjust personnel structure & 24 & 21 & 3 & 88 \\
\hline Reduce strain & (3) & $(2)$ & $(\mathrm{I})$ & $(67)$ \\
\hline Hire (prospective) teachers with migration background & $(21)$ & (19) & $(2)$ & $(90)$ \\
\hline Initiate human resource development processes (teachers) & 31 & 33 & 2 & 94 \\
\hline Consider experts/already existing expertise & (6) & (8) & $(2)$ & $(75)$ \\
\hline Introduce coaching, team meetings, tandems or collegial consulting & (6) & (6) & $(0)$ & $(100)$ \\
\hline Trainings and qualification interventions (for teachers) & (19) & (19) & $(0)$ & $(100)$ \\
\hline Develop intercultural competence (cognitive-emotional) & 46 & 45 & 7 & 98 \\
\hline Acquire and convey knowledge and skills & $(25)$ & $(21)$ & (4) & $(84)$ \\
\hline Develop pedagogical intercultural competencies & $(21)$ & (24) & (3) & (88) \\
\hline Reinforce social cooperation & 19 & 17 & 2 & 89 \\
\hline Develop social competencies & (3) & (3) & $(0)$ & $(100)$ \\
\hline Notice and solve concrete conflicts (all) & (7) & (6) & (I) & (86) \\
\hline Enable discussions & (9) & (8) & (I) & (89) \\
\hline
\end{tabular}


Table I. (Continued)

\begin{tabular}{lllll}
\hline & total & corr & non & $\%$ \\
\hline Develop the organization 'school' as a whole & 184 & 193 & 11 & 95 \\
Involve all stakeholders in school & 31 & 39 & 8 & 79 \\
Enable participation for everyone & $(5)$ & $(8)$ & $(3)$ & $(63)$ \\
Management levels as role models & $(7)$ & $(7)$ & $(0)$ & $(100)$ \\
Consider power structures and levels & $(4)$ & $(8)$ & $(4)$ & $(50)$ \\
Integrate actors and perspectives & $(10)$ & $(11)$ & $(1)$ & $(91)$ \\
Consider societal aspects of school life & $(5)$ & $(5)$ & $(0)$ & $(100)$ \\
Open school outwardly & 16 & 16 & 0 & 100 \\
Promote parental work and 'get parents into school' & $(5)$ & $(5)$ & $(0)$ & $(100)$ \\
Include external cooperation partners & $(11)$ & $(11)$ & $(0)$ & $(100)$ \\
Define and measure quality and development & 33 & 33 & 0 & 100 \\
Carry out ethnic monitoring & $(5)$ & $(5)$ & $(0)$ & $(100)$ \\
Carry out situation analysis & $(5)$ & $(5)$ & $(0)$ & $(100)$ \\
Measure and evaluate quality and development & $(12)$ & $(12)$ & $(0)$ & $(100)$ \\
Set up quality criteria and development goals & $(11)$ & $(11)$ & $(0)$ & $(100)$ \\
Determine consistent language concepts & 26 & 26 & 2 & 100 \\
Introduce translanguaging & $(7)$ & $(7)$ & $(0)$ & $(100)$ \\
Introduce only German as educational language & $(6)$ & $(6)$ & $(0)$ & $(100)$ \\
Enable personal sequence of foreign languages & $(1)$ & $(2)$ & $(1)$ & $(50)$ \\
Introduce German as the second language & $(7)$ & $(7)$ & $(0)$ & $(100)$ \\
Agree on one language concept & $(5)$ & $(4)$ & $(1)$ & $(80)$ \\
Counteract differentiation at school level & 33 & 33 & 0 & 100 \\
Counteract ethnitization and attributions & $(9)$ & $(9)$ & $(0)$ & $(100)$ \\
Counteract racism and discrimination & $(9)$ & $(9)$ & $(0)$ & $(100)$ \\
Counteract role schemes, stereotypes and prejudices & $(5)$ & $(5)$ & $(0)$ & $(100)$ \\
Counteract exclusion and propaganda & $(10)$ & $(10)$ & $(0)$ & $(100)$ \\
Develop intercultural pedagogical school concepts & 29 & 29 & 0 & 100 \\
Put structural measures in place & 13 & 13 & 0 & 100 \\
Cope with admission and issues of dropout rates (of students) & $(3)$ & $(3)$ & $(0)$ & $(100)$ \\
Introduce preparation courses, remedial classes or transition classes & $(3)$ & $(3)$ & $(0)$ & $(100)$ \\
Allow full-time education & $(4)$ & $(4)$ & $(0)$ & $(100)$ \\
Introduce learning space concepts & $(3)$ & $(3)$ & $(0)$ & $(100)$ \\
Embed interculturalism in administrative processes & 3 & 4 & 1 & 75 \\
\hline
\end{tabular}

classroom. Consequently, the native language of the individual students is pushed into the background. In order to prevent this and show appreciation for other languages, experts suggest other ways, such as enabling student to have their own personal sequence of foreign languages. Furthermore, the concepts of translanguaging as well as a popular German concept called 'German as an educational language' were mentioned, in which German is treated as the exclusive language and other languages are only allowed in negligible contexts, including birthday celebrations or to welcome students.

In addition, experts indicated that one of the conditions and goals of intercultural awareness and intercultural values was the development of a 'humanistic ethos' (18) among all participants. In particular, this included acceptance, appreciation and valuation, as well as sensitivity and empathy. Furthermore, the renunciation of deficit orientation was seen as basic for developing the aforementioned attitudes as well. 
Enable and apply reflection. Compared to the category rethink attitudes and values described above, this second category focuses less strongly on concrete issues regarding interculturalism. Rather, it is related to demands and tasks that enable and conduct the reflection of all actors and on all levels. However, although this second category aims at superordinate reflection processes, both categories are still connected. According to the opinions of the experts, those processes should not display a narrow view on culture and heterogeneity. Specific demands mentioned during the discussion were those related to self-reflection and change of perspective (39). Within this sub-category, in turn, were needs like taking different levels and roles into account (11), and learning (self-)reflection and change of perspective (24). In particular, practising reflection and changes of perspectives should already be initiated during the first phase of teacher training:

As an example one could use the prejudice that many immigrants treat women poorly. But what happens, if you ask yourself whether everything in that regard is unproblematic here? A change of perspective is particularly necessary in transitional classes, for example, where classes change constantly through students who come into class and others who are taken out of class. Problem awareness develops, if you take the perspective of another person and make it clear to people, who are in the inner circle, how it is to come into a closed group as a new person. [Exp_4_Gr1]

Enable concrete and practical application (2), recognize problems and develop problem awareness (6) and question existing structures through taking up criticism of power (3) were seen as the main goals of reflection processes. Following the experts' recommendations, it was suggested to dissociate from charged terms and gear towards issues like 'inclusion' in order to achieve these goals.

Advance instruction. In comparison to the remaining categories, the field of the development of teaching was not explained as specifically by the experts. It included broadening internal differentiation (5) in class, considering pedagogical-didactical concepts (4), as well as evaluating and enhancing concepts, methods, and materials for teachers (20). To review 'hidden curriculum' critically (2) was also seen as essential in this category.

Requirements related to consider language promotion and learning (14) in students were mentioned with regard to language. It is further noted that all demands and tasks should aim at gearing towards students (8), which was understood as including principles of enabling education for all (4) and creating identity/self-confidence of learners (4).

Address human resource development actively and promote social cooperation. One of the central areas of action with regard to intercultural school development was human resource development, which was mentioned 120 times during the discussions. Experts mentioned, with regard to this area, not only the recruitment of new teachers but also further education and training for personnel already working in the respective schools. In order to adjust the staff structure to already existing conditions of interculturalism within the schools, suggestions like reduce strain of teachers (3) and hire (prospective) teachers with migration backgrounds (21) were made. However, it was still questionable and unclear among the participating experts what exactly the tasks of teachers with migration backgrounds would be:

In a way this can be helpful for a migrational social opening of educating institutions, but the service of teachers with their own migration background is not necessarily effective, because teachers with migration backgrounds are not a priori interculturally competent or sensitive. Useful for reaching the goal of having teachers with migration backgrounds, however, can be programs that support students with migration backgrounds and avoid the comparatively high drop-out rates. [Exp_4_Gr1] 
Another demand or task with regard to intercultural school development was initiating human resource development processes (31), which also included considering experts/already existing expertise through extension and utilization of the aforementioned expertise for all fellow members (6). In addition, experts mentioned the demand of introducing coaching, team meetings, tandems or collegial consulting (6):

Teachers are often perceived as lone warriors or feel like those, particularly if problems occur. They are lucky or have bad luck regarding the support by their principal or the remaining teacher staff; that has to be applied more broadly or fixed institutionally. [Exp_11_Gr3]

Measures of teacher training and qualification interventions (19) were also part of this category. In that regard, a more differentiated picture of the content and goals of those events became obvious: On one hand, teachers should acquire and convey knowledge and skills about intercultural interpersonal skills (25), and on the other hand, they are supposed to develop pedagogical intercultural competencies (21) based on a broader understanding of competences. However, it is important to state that, although both demands are not the same, they are not mutually exclusive either:

Students claim a prayer room, seem to have very specific concepts about the fact that due to particular religions a separation or the like is needed, because they cannot pray together. The particular teacher asked the students about more details on the topic and also collected information on the web. She subsequently noticed that students had no idea about the topic, but rather just claimed something randomly. Conflicts often are not results of objectively existing religious beliefs, but rather develop based on defiance, lack of knowledge, entitlement mentality, etc. That is why teachers need more knowledge. [Exp_12_Gr3]

In addition to teachers' attitudes and training, experts also saw reinforcing social cooperation (19) as very important for human resource development. They emphasized that this was not just valid for teachers, but rather that human resources would affect all people involved in the school system. It is about developing social competencies further (3), enabling discussions in schools (9) and the ability of all involved to notice and solve concrete conflicts in everyday school life (7):

There were these two students from Switzerland, who refused to shake hands with a female teacher. Maybe those two boys just did not know what they are talking about. An enormous media response resulted out of that. At this point strategies of constructive, de-escalating way of handling such phenomena, if applicable, have to be developed. [Exp_9_Gr2]

Develop the organization 'school' as a whole. Organizational development is the area that has been mentioned the most by far (184). It is assumed that this was due to the fact that interculturalism and all related demands and tasks could only be successful and effective if they involve the school system as a whole and are supported by all people involved in it. In summary, it can be said that it is about developing intercultural pedagogical school concepts (29). Such concepts, but also the other arrangements related to intercultural school development, aim at counteracting differentiation at school level (33) by counteracting ethnitization and attributions (9) as well as role schemes, stereotypes and prejudices (5). Counteracting racism and discrimination (9) and exclusion and propaganda (5) were seen as ways to reach the aforementioned goal as well:

[. . .] that you talk about culture and ethnicity as a racist ascription is important; social ascriptions and processes exist and have to be questioned, because they otherwise lead into 'naturalization', which means that you treat people based on a particular rationale as if that was their nature to be one way or another. That is important for school, because it is always about perceptions of abilities, which means someone can either do something or not. This has to be reflected. [Exp_12_Gr3] 
Particularly important for achieving the success of an intercultural school on an organizational level was to involve all stakeholders in school (31), with management levels serving as role models (7). Furthermore, power structures and different power levels (4) and societal aspects of school life (5) would have to be considered throughout the process, and different actors and their perspectives have to be integrated into the processes (10). An additional demand was to open school outwardly (16), which was suggested could be realized in two ways: on one hand, by actively promoting parental work and 'getting parents into school' (5) and, on the other hand, by including external cooperation partners (11):

One central question is: 'How can I communicate with parents?' and a pragmatic approach opens up at that point; you, for example, need a pool of relevant people such as interpreters. [Exp_8_Gr2]

Define and measure quality and development (33) was seen as an additional core area with regard to organizational development. In this regard, it was particularly important that schools should be able to carry out situation analyses (5) or ethnic monitoring (5). Furthermore, they should be capable of setting up quality criteria and developmental goals (11) as well as measuring and evaluating quality and developmental processes independently (12):

It should be about putting participants in a position to answer questions like 'How does that work?' and 'How can I measure what we plan to do?'; that participants in school have to be enabled to evaluate school development; goals of teacher education and training are that students know concepts and are able to analyse them themselves, etc. It should be the goal that teachers are not dependent on external evaluations; in order to do that they need instruments, have to know the meaning of empirical evaluation - on a level that is manageable for a school! [Exp_5_Gr2]

However, the questions as to which quality characteristics apply or whether goals should be provided from the outside were not finally answered during the discussions. In intercultural school development processes, consistent language concepts should also be determined (26) on the school level, which would be mandatory and applied equally by all actors and participants. However, the experts did not agree during the discussion which particular concept this could be. One possibility as part of an extensive concept would be introducing translanguaging (7) as a concept in which equivalent and, at the same time, several other languages were allowed in communication, or introducing only German as the educational language at school (6), enabling a personal sequence of foreign languages (1), or to introduce German as the second language at the school (7). The concept of translanguaging, mentioned in this category, represents a mixture of languages, for example, English and Spanish (called 'Spanglish'), and is seen as representing cultural diversity (e.g. Creese \& Blackledge, 2010; Garcia \& Wei, 2014; Hornberger \& Link, 2012):

It is simply about the question, which language can legitimately be spoken in which way at school. [Exp_9_Gr2]

To conclude the examination of the demands and tasks of intercultural school development, a few more demands were mentioned that address putting structural measures in place (13) and interculturalism into administrative processes of a school in which interculturalism should be considered (3). With regard to structural measures, experts perceived concepts such as coping with admission and issues of dropout rates of students (3), for example, through preparation courses, remedial classes or so-called transition classes (3), but also structural changes with regard to allowing fulltime education (4) and introducing learning space concepts (3) as essential. 
Table 2. Comparison of school development models.

\begin{tabular}{|c|c|c|}
\hline Dalin (2005) & Karakaşoğlu et al. (201I) & Group discussions with experts \\
\hline & & Reassess attitudes and values \\
\hline & & Enable and apply reflection \\
\hline $\begin{array}{l}\text { Teaching } \\
\text { development }\end{array}$ & $\begin{array}{l}\text { Content-related, didactical and } \\
\text { curricular level } \\
\text { Individuals }\end{array}$ & Advance instruction \\
\hline \multirow{2}{*}{$\begin{array}{l}\text { Human resource } \\
\text { development }\end{array}$} & Personal level & \multirow{2}{*}{$\begin{array}{l}\text { Conduct human resource } \\
\text { development actively and } \\
\text { promote social collaboration }\end{array}$} \\
\hline & Social level & \\
\hline $\begin{array}{l}\text { Organizational } \\
\text { development }\end{array}$ & Structural, organizational level & $\begin{array}{l}\text { Develop the organization } \\
\text { school as a whole }\end{array}$ \\
\hline
\end{tabular}

\section{Discussion}

The present study explains demands and tasks that are essential with regard to the intercultural school development process. In particular, it shows which structures, measures, cooperation and attitudes are essential in order to open school and the school system for children and adolescents with migration backgrounds, as well as for their parents. Based on the acquired categorical system, a concept was developed to explain the concrete actions that have to be taken, based on the experts' points of view, in order for the process to be successful.

\section{Demands and tasks of intercultural school development}

The first research question aimed at clarifying whether the demands and tasks mentioned by the experts can be found in a similar way within the models of school development that have been postulated theoretically (see sections 'Dalin's model of school development' and 'Intercultural school development'). By comparing the results of the study to the aforementioned theoretical models, similarities between levels in the models and the mentioned aspects were found. In particular, five areas were identified, which are described further in Table 2.

It is important to note that the exact assignment of requirements revealed in the study to the theoretical models is not possible. In addition, transitions between particular levels and dimensions are uncertain, especially in school development processes. However, evidence for the fact that experts did not only consider 'classical areas', such as teaching, school and human resources, as important for intercultural school development, but rather consider values and reflections as being essential in that regard could be found as well. The theoretical model by Karakaşoğlu and her colleagues (2011) already partially includes this aspect in terms of gearing towards the individual and the social levels, respectively.

Which particular demands and tasks (such as structures, measures, cooperation, attitudes, etc.) are essential in intercultural school development processes from the experts' points of view was the goal of the second research question. Those that were identified throughout the discussions included reassessing attitudes and values, enabling and applying reflection, developing teaching further, enhancing human resource development actively, supporting social collaboration and improving the organization 'school' as a whole (see also Tables 1 and 2). The two last areas represent the most nominations, which is assumed to be due to the fact that these were of particular importance to the experts or the fact that they have less expertise with areas like the concrete development of teaching. 


\section{Practical implications: conditions of success}

The above-mentioned five areas of demands and tasks from the experts' points of view can be represented as five guiding principles of success (see sections 'Rethink attitudes and values', 'Enable and apply reflection', 'Develop teaching', 'Address human resource development actively and promote social cooperation' and 'Develop the organization "school" as a whole'):

- The organization 'school' has to be seen and developed further as a whole, while all levels and all actors have to be considered.

- School development represents an active, long-term and institutionally incorporated human resource development process, as well as support of social cooperation.

- The basis and permanent concomitant in the process of school development consist of the reassessment and improvement of attitudes and values and the enabling and applying of institutionalized reflection.

- Teaching has to be developed further in a culturally sensitive way as part of school development and has to be orientated towards the individual.

- Dealing with languages is a cross-sectional topic because it was found throughout all areas and, therefore, needs to be essentially handled on all levels.

The guiding principles that have been described as conditions for success with regard to intercultural school development can be embedded within the theoretical context mentioned above. Furthermore, they can provide empirical support for further theoretical models and serve as ways to facilitate differentiation with regard to practice.

\section{Methodological strengths, limitations and further research}

The group discussions, based on which the aforementioned areas have been developed, were structured in a way to enable participants to work on particular questions. Those gave the discussion a thematic focus, which represents one of the methodological strengths of the present study. This was particularly achieved by further questions, explanations, reasoning, examples and so on, enabling a more detailed description of the theoretical models. If a quantitative methodological approach would have been applied, these specifications would not have been accounted for (e.g. Coolican, 2014). The fact that participants cannot express everything they can think of with regard to a topic can be seen as a limit of this method. This would, for example, be the case if it seems unusual to them to represent a divergent single opinion, if there are relatively dominant discussion partners, or if they might not want to express something which would not be socially desirable (e.g. Cargan, 2007). A second limiting factor is that only German experts participated in the group discussions of the study. While this might represent solely German points of view and, thus, limit the generalization of the findings, these circumstances, at the same time, offer possibilities for further research. Possible extensions of the present study would include transferring the approach to other European and non-European countries, and contrasting experts from different countries to reveal further generalizable insights into tasks and demands for a successful intercultural school development process.

Finally, based on the revealed categories, guidelines for teachers and principals in the form of a concept of intercultural school development could be developed in order to apply the findings to school practice. 


\section{Funding}

The author(s) disclosed receipt of the following financial support for the research, authorship, and/or publication of this article: This work was supported by the European Union/Asylum, Migration and Integration Fund $(A M I F)$, under grant number AM14-00208.

\section{References}

Action Commission Education [Aktionsrat Bildung] (2016). Integration durch Bildung. Migranten und Flüchtlinge in Deutschland [Integration through education: Migration and refugees in Germany]. Muenster, Germany: Waxmann.

Agar, M., \& MacDonald, J. (1995). Focus groups and ethnography. Human Organization, 54(1), 78-86.

Barbour, R. (2007). Doing focus groups (Book 4 of the SAGE Qualitative Research Kit). London, England: SAGE.

Benedict, R. (1954). The chrysanthemum and the sword: Patterns of Japanese culture. Rutland, VT: Charles E. Tuttle.

Bos, W. (1989). Reliabilität und Validität in der Inhaltsanalyse [Reliability and validity in the content analysis]. In W. Bos, \& C. Tarnai (Eds.), Angewandte Inhaltsanalyse in Empirischer Pädagogik und Psychologie [Applied content analysis in the science of empirical science of education and psychology] (pp. 61-72). Muenster, Germany: Waxmann.

Cargan, L. (2007). Doing social research. Lanham, MD: Rowman \& Littlefield.

Catarci, M., \& Fiorucci, M. (Eds.). (2016). Intercultural education in the European context: Theories, experiences, challenges. London, England: Routledge.

Coffey, A., \& Atkinson, P. (1996). Making sense of qualitative data: Complementary research. Thousand Oaks, CA: SAGE.

Coolican, H. (2014). Research methods and statistics in psychology. London, England: Psychology Press.

Creese, A., \& Blackledge, A. (2010). Translanguaging in the bilingual classroom: A pedagogy for learning and teaching? The Modern Language Journal, 94, 103-105.

Dalin, P. (1978). Changes to educational change. Basingstoke, UK: Macmillan.

Dalin, P. (2005). School development theories and strategies: An international handbook. London, England: Continuum.

Dalin, P., Rolff, H. G., \& Kleekamp, B. (1993). Changing the school culture. London, England: Continuum.

Eurostat. (2015). Migration and migrant population statistics. Retrieved from http://ec.europa.eu/eurostat/ statistics-explained/index.php/Migration_and_migrant_population_statistics

Garcia, O., \& Wei, L. (2014). Translanguaging: Language, bilingualism and education. London, England: Palgrave Pivot.

Giddens, A. (1999). Runaway world: How globalization is reshaping our lives. London, England: Routledge.

Hall, S. (1997). Representation: Cultural representations and signifying practices. New York: SAGE.

Haque, M. S. (2004). New public management: Origins, dimensions, and critical implications. In K. Tummala (Ed.), Public administration and public policy (pp. 209-228). Oxford, UK: Eolss Publishers.

Herder, J. G. (1995). Ideen zur Philosophie der Geschichte der Menschheit [Ideas for a philosophy concerning a history of mankind]. Berlin, Germany: Heise.

Hollander, J. A. (2004). The social context of focus groups. Journal of Contemporary Ethnography, 33, 602-637.

Honneth, A. (1996). The struggle for recognition: The moral grammar of social conflicts. Cambridge, MA: MIT Press.

Hornberger, N., \& Link, H. (2012). Translanguaging and transnational literacies in multilingual classrooms: A bilingual lens. International Journal of Bilingual Education and Bilingualism, 15, 261-278.

Hsieh, H. F., \& Shannon, S. E. (2005). Three approaches to qualitative content analysis. Qualitative Health Research, 15, 1277-1288.

International Organization for Migration. (2015). World migration report. Retrieved from http://publications. iom.int/system/files/wmr2015_en.pdf 
Karakaşoğlu, Y., Gruhn, M., \& Wojciechowicz, A. (2011). Interkulturelle Schulentwicklung unter der Lupe. (Inter)nationale Impulse und Herausforderungen für Steuerungsstrategien in Bremen [Examining intercultural school development closely. (Inter)national impulses and challenges for controlling strategies in Bremen]. Münster, Germany: Waxmann.

Kiel, E., Syring, M., \& Weiss, S. (2016). How can intercultural school development succeed? The perspective of teachers and teacher educators. Pedagogy, Culture and Society. Epub ahead of print 31 October. DOI: $10.1080 / 14681366.2016 .1252421$.

Kvale, S. (1995). The social construction of validity. Qualitative Inquiry, 1(1), 19-40.

Lahdenperä, P. (2009). How to develop an intercultural school: Experiences from Sweden. In M. T. Talib, J. Loima, P. Heini, \& S. Patrikainen (Eds.), Dialogs on diversity and global education (pp. 107-122). Frankfurt, Germany: Peter Lang.

MAXQDA. (2011). [Qualitative data analysis software]. Berlin, Germany: VERBI Software.

Mayring, P. (2000). Qualitative content analysis. Forum: Qualitative Research, 1(2). Retrieved from http:// www.qualitative-research.net/index.php/fqs/article/view/1089

McLuhan, M. (1962). The Gutenberg Galaxy: The making of typographic man. Toronto, Ontario, Canada: University of Toronto Press.

Morgan, D. L. (1997). Focus groups as qualitative research (2nd ed.). Thousand Oaks, CA: SAGE.

Morse, J. M., \& Field, P. A. (1995). Qualitative research methods for health professionals (2nd ed.). Thousand Oaks, CA: SAGE.

Patton, M. Q. (2002). Qualitative research and evaluation methods. Thousand Oaks, CA: SAGE.

Schratz, M., \& Steiner-Loeffler, U. (1999). Die lernende Schule. Arbeitsbuch pädagogische Schulentwicklung [The learning school: Workbook educational school development]. Weinheim, Germany: Beltz.

United Nations Department of Economic and Social Affairs (2013). International migration report 2013. Retrieved from http://www.un.org/en/development/desa/population/migration/publications/migrationreport/docs/MigrationReport2013.pdf 